\title{
A Monoclonal Antibody, Py, Distinguishes Different Classes of Hippocampal Neurons
}

\author{
Peter L. Woodhams, ${ }^{1}$ Michael Webb, ${ }^{2}$ D. John Atkinson, ${ }^{1}$ and P. John Seeley ${ }^{1}$ \\ 'The Norman and Sadie Lee Research Centre, Laboratory of Neurobiology, National Institute for Medical Research, The \\ Ridgeway, London NW7 1AA, and 'Sandoz Institute, London WC1E 6BN, England
}

\begin{abstract}
A monoclonal antibody, Py, was produced by immunizing mice with a glycoprotein fraction isolated from 3-week-old rat hippocampus. Py antibodies gave strong immunocytochemical staining of the perikarya and dendrites of large neurons in many areas of the rat brain, including the cerebral cortex, hippocampus, cerebellum, brain stem, and olfactory bulb. Immunoelectron microscopy showed the antigen to be predominantly intracellular, although its presence on the neuronal cell surface was not excluded. The antibody gave differential staining of adult hippocampal neurons, large pyramids of field CA3 being strongly immunoreactive, while CA 1 pyramids and the dentate granule cells were unstained. Some interneurons were positive in each of the hippocampal fields. In developing hippocampus, the Py antigen appeared by the middle of the first postnatal week, and the adult pattern of staining was achieved by the end of the second week. Immunoblotting showed the antigen to have a relative mobility of $146 \mathrm{kDa}$ with an additional faint band at $166 \mathrm{kDa}$. Differential Py staining of neurons was seen in dissociated cultures of embryonic hippocampus and in subdissected hippocampal fragments transplanted into adult host brains. This antibody can therefore be used for identification of hippocampal neurons that have been removed from their normal anatomical context.
\end{abstract}

We have initiated a program of production of monoclonal antibodies to hippocampal glycoproteins with the aim of generating specific markers for neurons of this brain area, a region whose anatomy is relatively simple and well understood and which is particularly well suited to experimental manipulation and analysis (e.g., Zhou et al., 1985; C.-F. Zhou, R. J. Morris, and $\mathrm{G}$. Raisman, unpublished observations). The antibodies will be used in studies of neural transplants and cultures of hippocampus. A number of previous reports describe antibodies that label different classes of hippocampal neurons but with varying degrees of specificity. Miller and Benzer (1983) showed that antibodies 2F12 and 3F12, raised against Drosophila immunogen, distinguished between dentate granule and pyramidal neurons in sections of human hippocampus. Antibody $6 \mathrm{~A} 2$ from the same laboratory appeared to be selective for occasional stel-

\footnotetext{
Received Aug. 15, 1988; revised Oct. 26, 1988; accepted Oct. 28, 1988.

We wish to thank Stuart Docherty for preparation of antigen. Pauline Field for help with subdissections, Wendy Berg for help with the hippocampal transplants, and Geoffrey Raisman for comments on the manuscript.

Correspondence should be addressed to Peter L. Woodhams at the above adcress.

Copyright (C) 1989 Society for Neuroscience $0270-6474 / 89 / 062170-12 \$ 02.00 / 0$
}

late cells, while 44.1 had a broader specificity (Hinton et al., 1988). Antibodies G6E3 of Moskal and Schaffner (1986), 1F4 of Sajovic et al. (1986) and Cat-301 of Hendry et al. (1988) recognize both pyramids and other cell types. VC1.1 and VC5.1 (Arimatsu et al., 1987) likewise appear to have a broad pattern of hippocampal staining, although with fewer positive pyramids in field CA 1 than in other hippocampal fields. Our present strategy for generating antibodies is one that has proved to be successful in the past (Webb and Woodhams, 1984a, b), and involves preparing immunogen from a glycoprotein fraction isolated by affinity chromatography on a plant lectin column and depleting it of the highly immunogenic protein Thy- 1 . The antibody described here (Py) selectively stains neurons in hippocampus and other brain regions, and its application to cell identification in neural grafts and in culture is reported.

\section{Materials and Methods}

Animals and surgical procedures. Rats were of the inbred PVG strain. Adult animals were 200-250 gm females. Embryonic (E) age was dated from the presence of a vaginal plug (E0). For grafting experiments, hippocampi were dissected from about 10 E18 fetuses and cut transversely into $1 \mathrm{~mm}$ slices. Each slice was subdissected with fine tungsten needles into fields CA1, CA3, dentate gyrus anlage, and a "transitional" zone made up of a portion of the dentate anlage and some pyramidal cells of fields CA4 and CA3. Details of this procedure will be published elsewhere (Field et al., unpublished observations). Ten pooled fragments of each type were suspended in a plasma clot (Lindsay et al., 1987) and transplanted unilaterally through a $0.8-\mathrm{mm}$-diameter glass cannula into the hippocampus of adult rat recipients at coordinates $3.0 \mathrm{~mm}$ posterior to the bregma, $4.5 \mathrm{~mm}$ lateral, and $9.0 \mathrm{~mm}$ deep (de Groot, 1967). After a survival time of 12 weeks, brains containing grafts were prepared for light microscopy as described below. Serial polyester wax sections were cut through the cntirc length of each graft to assess the cell types present, and selected areas were stained with monoclonal antibody Py.

Production of monoclonal antibody Py. Glycoprotein fractions were prepared from P21 rat or P28 calf hippocampus by affinity chromatography on lentil lectin- or wheat germ agglutinin-Sepharose. All extraction and chromatography steps were carried out at $4^{\circ} \mathrm{C}$. Phenylmethylsulphonyl fuoride (PMSF), 2 mM, and EDTA, 2 mM, were present in all buffers to inhibit proteases. Hippocampi (not membrane fractions) were homogenized in $10 \times$ their volume of $2 \%(\mathrm{wt} / \mathrm{vol})$ deoxycholate buffer according to the method of Webb and Woodhams (1984a) except that initial extraction was for 30-60 min and that the samples were then sonicated (MSE Soniprep 150, 3 cycles of $10 \mathrm{sec}$ of $50 \%$ power and 10 $\mathrm{sec}$ wait) prior to clarification by centrifugation. The deoxycholate extract was chromatographed on a lectin-Sepharose column using methods similar to thosc prcviously described (Barclay et al., 1975; Webb and Woodhams, 1984a) and the eluate subsequently depleted of the highly immunogenic protein Thy-1 using a mouse-anti-Thy-1 column (8 $\mathrm{mg}$ MRC OX7 antibody/ml Sepharose) by the method of LetarteMuirhead et al. (1975) (except for omission of the precolumn and some alterations in chromatographic parameters). Three volumes of absolute ethanol were added to pooled nonbinding fractions and the mixture stored at $-20^{\circ} \mathrm{C}$ for $24-48 \mathrm{hr}$ before precipitated protein was separated 
by centrifugation. The pellet was taken up in water and its concentration determined by the method of Hartree (1972). Antibody Py was derived from an animal immunized with rat lentil lectin-binding proteins $(50$ $\mu \mathrm{g}$ doses). However, the 4 combinations of lectin and tissue source generated similar immune responses.

Individual female $\mathrm{Balb} / \mathrm{c}$ mice (6-8 weeks old) were immunized subcutaneously with $50 \mu \mathrm{g}$ or $150 \mu \mathrm{g}$ aliquots of glycoprotein. The first 2 immunizations (complete Freund's adjuvant) were at an interval of 1 week. Subsequent immunizations (incomplete Freund's adjuvant, $7-10$ in number) were given at intervals of 2-3 weeks. Serum from these animals was tested by the ELISA described below. The titer for the Py animal was 1:3000. Animals were boosted $3 \mathrm{~d}$ prior to fusion by intravenous injection of the appropriate dose of immunogen in PBS.

Production of hybridomas and cloning was carried out by the method of Webb and Woodhams (1984a), except that NSO myeloma cells were used instead of P3X63Ag8. Cell fusion was achieved by treatment with $50 \%$ polyethylene glycol for $2 \mathrm{~min}$ at $37^{\circ} \mathrm{C}$. Primary screening was carried out by ELISA as follows. Hippocampi were dissected from P21 rats and homogenized in 10 vol ice-cold, calcium- and magnesium-free PBS. This preparation was diluted 1:50 in $0.1 \mathrm{~m} \mathrm{NaHCO}, \mathrm{pH} \mathrm{9.0,} \mathrm{and}$ added to flexible microtiter plates $(100 \mu \mathrm{l} /$ well $)$. The plates were left overnight at $4^{\circ} \mathrm{C}$ and then incubated at room temperature for $60 \mathrm{~min}$ in PBS containing 3\% BSA. Then $100 \mu 1$ of test supernatant was applied per well. After $60 \mathrm{~min}$ at $4^{\circ} \mathrm{C}$ the wells were washed $(5 \times, \mathrm{PBS})$ and 50 $\mu$ peroxidase-coupled sheep-anti-mouse IgG $\mathrm{F}(\mathrm{ab})_{2}^{\prime}$ fragment (Amersham International, 1:500) was added per well. After $1 \mathrm{hr}$ at $4^{\circ} \mathrm{C}$, the wells were washed and peroxidase was visualized using $o$-phenylenediamine (Webb and Woodhams, 1984b). The Py antibody was found to be of the IgM isotype by an ELISA employing class-specific reagents (ICN Immunochemicals).

Immunoblotting procedures. Dissected brain tissue was homogenized in approximately $5 \mathrm{vol}$ of ice-cold $(25 \mathrm{~mm}$ Tris- $\mathrm{HCl}, 2.0 \mathrm{~mm}$ PMSF, $2.5 \mathrm{~mm}$ iodoacetamide, $\mathrm{pH} 6.8$ ). The homogenates were frozen on dry ice within $15 \mathrm{~min}$ of killing the rats. After thawing, protein contents were determined on an aliquot of each sample using the method of Lowry et al. (1951), and samples were then dissolved by boiling for 5 min in SDS sample buffer $(2.3 \%$ SDS, $62.5 \mathrm{~mm}$ Tris- $\mathrm{HCl}, 10 \%$ (vol/ vol) glycerol, $\mathrm{pH} \mathrm{6.8)} \mathrm{to} \mathrm{give} \mathrm{protein} \mathrm{concentrations} \mathrm{of} 1 \mathrm{mg} / \mathrm{ml}$. These samples were stored as aliquots at $-70^{\circ} \mathrm{C}$ until used.

Polyacrylamide gels $(7.5 \%, 3 \%$ stacking gel) were run at constant current ( $7 \mathrm{~mA}, 16 \mathrm{hr}$ ) using the buffer system of Laemmli (1970). Resolved proteins were electrophoretically transferred to nitrocellulose in $25 \mathrm{~mm}$ Tris, $192 \mathrm{~mm}$ glycine, $\mathrm{pH} 8.8$ for $6 \mathrm{hr}$ at $25 \mathrm{~mA}$. Blots were then incubated overnight in PBS, $0.1 \%$ Triton X-100, 3\% BSA. They were stained for $90 \mathrm{~min}$ at $4^{\circ} \mathrm{C}$ in Py-conditioned supernatant and then washed in PBS, $0.1 \%$ Triton X-100, 1 mM EDTA ( 4 vol over $2 \mathrm{hr}$ ). Blots were then incubated for $2 \mathrm{hr}$ in PBS containing 3\% BSA and 3$4 \times 10^{5} \mathrm{cpm} / \mathrm{ml}$ of ${ }^{125}$ I-labeled $\mathrm{F}(\mathrm{ab})_{2}{ }_{2}$ sheep anti-mouse IgG (Amersham International). After further washing as above, bound antibody was detected by autoradiography using Kodak X-Omat film $\left(1-3 \mathrm{~d}\right.$ at $-70^{\circ} \mathrm{C}$ ).

Immmunohistochemistry. Initial screening of hybridoma-conditioned culture medium was carried out on both unfixed and acid alcohol-fixed 10 cryostat sections of adult rat forebrain, incubated overnight at $4^{\circ} \mathrm{C}$. For further analysis of promising clones, unfixed, acid alcohol-, and paraformaldehyde-fixed cryostat sections of forebrain and cerebellum were employed. Sites of antibody binding were revealed with a 1 $\mathrm{hr}$ incubation at room temperature in rabbit anti-mouse $\mathrm{gGG}(\mathrm{ICN} \mathrm{Im}-$ munochemicals, $1: 100$ in PBS, $1 \%$ BSA), followed by a similar incubation in monoclonal mouse peroxidase-antiperoxidase (ICN clone P6/ $38,1: 400$ ). Sections were developed for 5-10 min with diaminobenzidine (100 $\mathrm{mM} \mathrm{NaH}_{2} \mathrm{PO}_{4}, 0.05 \%$ DAB, $10 \mathrm{~mm}$ imidazole, $0.006 \% \mathrm{H}_{2} \mathrm{O}_{2}$, $\mathrm{pH}$ 5.8). Some sections were counterstained with thionin or enhanced by the addition of $0.015 \%$ cobaltous chloride to the reaction solution. Other sections were intensified using a silver-enhancement method involving a $5 \mathrm{~min}$ incubation in $0.1 \%$ sodium tetrachloroaurate (III), 5 min in neutralized $2.5 \%$ sodium sulfide, followed by physical development of silver for $3 \mathrm{~min}$ (Gallyas et al., 1982). In each experiment, negative controls were run using normal mouse serum $(1: 1000)$ and further tests of specificity provided by incubations in a variety of monoclonal antibodies with known patterns of staining.

More detailed analysis of Py antigen distribution was carried out on acid alcohol-fixed tissue embedded in polyester wax (BDH, Poole, UK) and sectioned at $7 \mu \mathrm{m}$. Following identification of the Py antibody as being of the IgM class, the protocol was changed such that rabbit antimouse IgM (ICN Immunochemicals, 1:50) was used for the second layer and sheep anti-rabbit IgG conjugated to HRP (1:250, gift from Dr. R. J. Morris) for the third layer. Py ascitic fluid (1:500-1:1000) was used as an alternative to tissue culture supernatant.

Immunocytochemistry at the ultrastructural level was carried out on $60 \mu \mathrm{m}$ vibratome slices of adult rat forebrain. Brains were fixed by perfusion with degassed, ice-cold $0.5 \%$ paraformaldehyde, $0.5 \%$ glutaraldehyde, $0.1 \mathrm{M}$ phosphate buffer, pH 7.4 (Morris and Barber, 1983). Dissected blocks were postfixed for $2 \mathrm{hr}$ at $4^{\circ} \mathrm{C}$. Following immunostaining of the vibratome slices as described above, they were osmicated for $1 \mathrm{hr}$ in $1 \% \mathrm{OsO}_{4}$, dehydrated in ethanol (staining in $0.2 \%$ uranyl acetate for $30 \mathrm{~min}$ at the $96 \%$ stage), and flat-embedded in TAAB embedding resin on glass slides coated with a mould-releasing compound (Formen-Trenmittel Hobby Fluid, Hobby Wholesale, London SW27 $0 \mathrm{HH}$ ). Ultrathin sections were viewed without further contrast enhancement.

Cell cultures. Dissociated cultures of hippocampus were prepared as described by Seeley and Field (1988). Cells from subdissected E18 hippocampi were plated into wells of a 24 well tissue culture plate at an initial density of $9 \times 10^{4}$ cells $/ \mathrm{cm}^{2}$. After $17 \mathrm{~d}$ in vitro, the cultures were fixed for $10 \mathrm{~min}$ in acid alcohol, and immunoperoxidasé staining with Py supernatant was carried out as described above.

\section{Results}

Derivation of the Py clone and the distribution of its antigen in adult rat brain

Of 99 supernatants (from 4 fusions) that gave moderately to strongly positive reactions in the ELISA, 72 gave a positive reaction on forebrain sections; 41 of these supernatants merited further study in that they gave nonuniform staining patterns. Thirteen lines were subsequently cultured to monoclonality by limiting dilution. Of the ELISA-positive group (72 supernatants), many (59) stained cell nuclei (most strongly after paraformaldehyde fixation); 10 supernatants stained blood vessels, the choroid plexus, or meninges. Most of the supernatants stained fixed sections more weakly than unfixed ones.

Clone number 11A4 was selected for detailed analysis because its antibody showed a striking differential pattern of staining of neurons of the various hippocampal fields. Since our results show that this antibody is a marker for a subset of pyramidal neurons, we have given it the name "Py." An additional reason for studying this particular clone was that immunoreactivity to Py antibody survived a moderate degree of fixation, enabling investigation of the distribution of the antigen at an ultrastructural level. Within the hippocampus the most striking staining with Py was seen in the large pyramidal cells of field CA3 (Figs. $1, a, b ; 2 a)$. Their perikarya and main dendrites were intensely immunoreactive; nuclei were unstained. At high magnifications, the DAB reaction product in the cytoplasm appeared to be filamentous (e.g., Fig. 1b). Because of the intense internal staining of these cells, it was not possible to ascertain from polyester wax material whether antigen was also present on their surfaces, although in some sections surface staining of cortical pyramidal neurons could be observed. Py immunoreactivity was never seen in non-neuronal cells. Staining of pyramidal cells of field CA4 was similar to that for CA3 pyramids. Also, like the CA3 pyramids, interneurons in the hilus of the dentate gyrus were strongly stained, and numerous Py-positive processes of different thicknesses could be seen coursing among them, presumably representing both axons and dendrites (Fig. 1c). Positive nonpyramidal cells were also present in fields CA1-3, but they were relatively infrequent (see below).

In contrast to these positive cells, the dentate granule neurons were unstained in polyester wax sections (Figs. 1, $c, d, 2 a$ ). (Apparent nuclear stain in Figures $1, c, d$ and 2 is due to the 

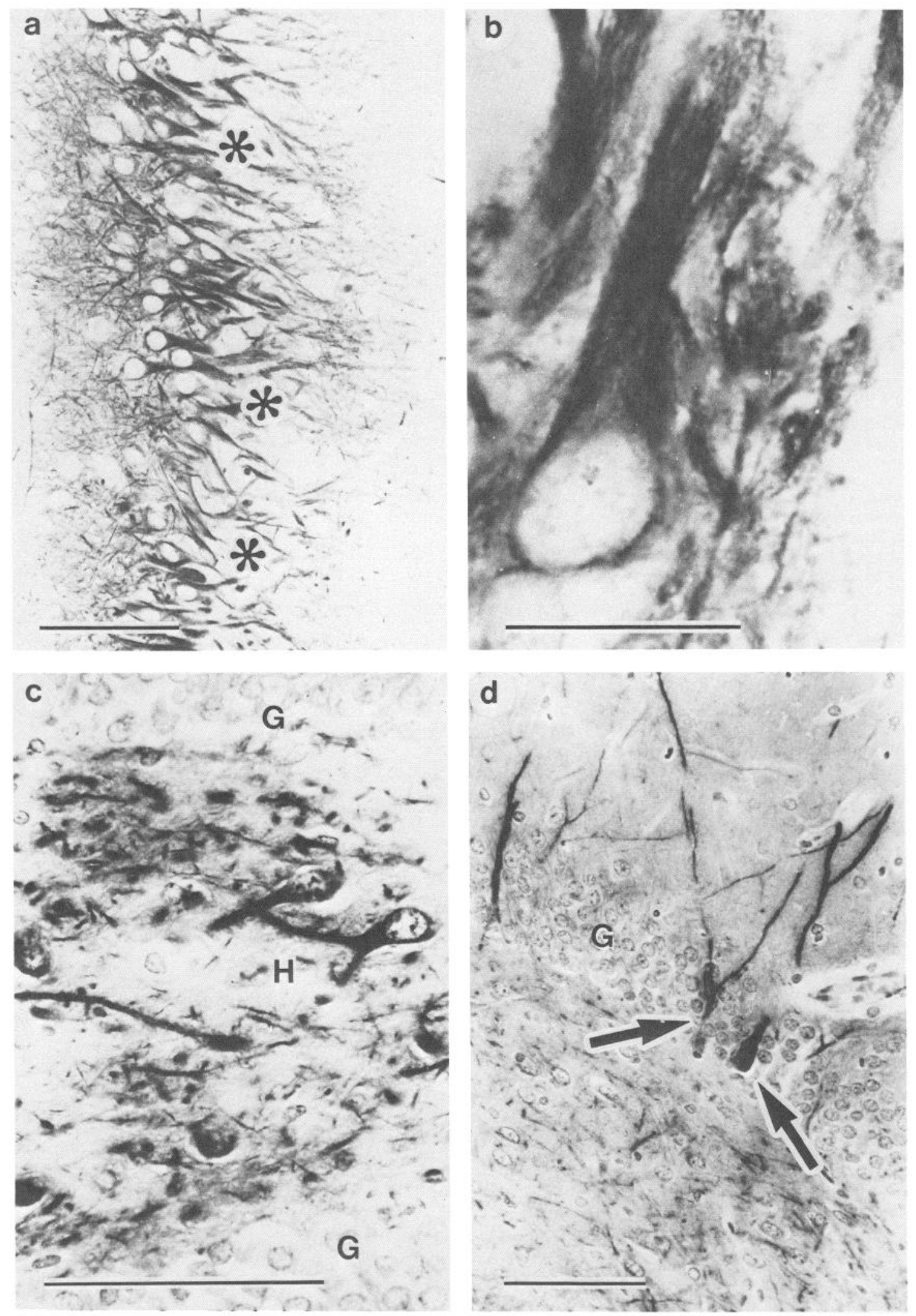

Figure 1. Immunostaining with Py on polyester wax sections of adult rat hippocampus. $a$ and $b$, Pyramidal cells of field CA3 (note the lack of immunoreactivity in mossy fibers of the stratum lucidum, $\left.{ }^{*}\right) ; c$ and $d$, dentate gyrus, with cobalt intensification. Granule neurons $(G)$ are unstained, in contrast to the hilar interneurons $(H)$ and the basket cells (arrows). Scale bars: $a, c$, and $d, 100 \mu \mathrm{m} ; b, 20 \mu \mathrm{m}$. 
use of cobalt intensification.) The lack of staining in dentate granule cells and their processes was also evident from the pale appearance of the mossy fiber terminal field in the stratum lucidum (Fig. 1a). The difference in immunoreactivity between CA3 pyramidal and dentate granule cells is relative rather than absolute: in unfixed sections, very weak staining could be seen in dentate granule cells, but this was not observed in the fixed material used for histological analysis, even when fixation was relatively mild. The dentate granular layer was not totally devoid of immunoreactivity since occasional large, immunopositive cells and isolated thick dendritic processes were scattered between the granule cells (Fig. 1d). From their morphology and position, these cells were presumed to be pyramidal basket neurons (Amaral, 1978; Ribak and Anderson, 1980).

The CA1 hippocampal field, which comprises smaller pyramidal cells that lack the mossy fiber input of CA3, was also distinguished from the latter by the absence of Py immunoreactivity in the pyramidal neurons (Fig. 2, $a-c$ ). The difference in staining intensity between large and small pyramids was most striking in the transitional zone between CA1 and CA3, field CA2 (Fig. $2 b$ ). The larger pyramids had a prominent nucleolus and high levels of Py immunoreactivity, whereas the smaller CAl cells were unstained and had heterochromatic nuclei. As in the dentate gyrus, a few positive perikarya werc scattered among the unstained CA1 pyramidal cells. Thick, varicose Pypositive processes running radially in the stratum radiatum were evident in all hippocampal fields and were especially noticeable in CAl (Fig. 2c). As the pyramidal cell layer became wider, where CA1 merged into the subiculum, Py staining became apparent in many but not all neurons (Fig. $2 d$ ), with variable intensity among those that were pusitive. Positive interneurons were clearly identifiable below the pyramidal cell layer in the stratum oriens of all hippocampal fields. They were predominantly of medium size with horizontally orientated dendrites. Stained axons were also observed in the alveus and the fimbria.

A detailed analysis of the distribution of Py staining in all brain regions will not be presented here, but the major features of its extra-hippocampal localization will be given. Intense Py immunoreactivity was present in subpopulations of cells in many different brain areas. Such cells were always ncurons and were predominantly large in size. They included cerebral cortical pyramidal cells of both layers III and V (Fig. $3 a$ ), cerebellar Purkinje cells (Fig. 3b), olfactory bulb mitral cells - their dendrites in the olfactory glomeruli being especially noticeable-and numerous magnocellular neurons of the hypothalamus, tegmentum (Fig. 3d), and brain stem. In the cerebral cortex, stained pyramids were seen in all regions, with the exception of the periand entorhinal cortices below the rhinal fissure. Staining appeared to be mostly in perikarya and the main dendritic branches: the finer branches and dendritic thorns, for example, were not visible with Py staining, although the coarser, interweaving processes of pyramidal cell apical dendrites were clearly visible in cortical lamina I (Fig. 3c). However, staining was not confined to cell bodies and dendrites: Py-positive axons were seen in many locations. For example, they were clearly evident emanating from cerebellar Purkinje cells where they contrasted with the unstained cells of the internal granule layer (Fig. 3b).

\section{Ultrastructural localization of Py antigen in hippocampus}

Analysis of Py staining under the electron microscope was undertaken with the aim of identifying immunoreactive cell processes and of providing more information on the subcellular distribution of the antigen. Py-stained CA 3 pyramidal cell bodies showed an even distribution of reaction product throughout the cytoplasm with no obvious restriction to any particular organelles (Fig. 4a). The interior of the mitochondria and the whole of the nucleus were unstained. Staining of the outer surface of the plasmalemma was not particularly prominent for perikarya, though reaction product was possibly associated with the surfaces of some dendritic profiles (Fig. 4c).

Outside the pyramidal cell layer, most of the stained profiles were obliquely sectioned dendrites (Fig. 4, b,c), some of which could be identified as arising from CA3 pyramids by the characteristic mossy fiber terminals contacting them (Fig. 4b). Under the present fixation conditions, DAB reaction product within such dendritic profiles usually had a flocculent appearance. Not all stained profiles were dendrites: some were quite clearly axonal (Fig. $4 d$ ).

\section{Development of Py immunoreactivity}

Animals were examined for Py immunoreactivity over a range of developmental ages with the aim of defining the time course of development of staining within hippocampus. Py immunoreactivity was not observed in the E17 or E18 rat brain. Postnatal animals were examined at P0, P5, P7, P10, and P14. There was no Py immunoreactivity in the newborn hippocampus, although in the septofimbrial nucleus strong staining was seen in a small group of cells that had transversely orientated processes. Staining was at background levels in all other brain areas examined at P0. By P5, the first traces of hippocampal staining could be seen in the cell bodies and apical dendrites of some CA3 pyramids (Fig. 5a). The intensity of staining gradually increased and was moderate at $\mathrm{P} 7$, although more diffuse than in the adult. By the middle of the second week, stained processes, presumed to represent both dendrites and axons, were visible both above and below the pyramidal cell layer (Fig. 5c). CA3 pyramidal cells still varied in the intensity of their immunoreactivity. By P14, the pattern of staining was equivalent to that in the adult hippocampus (Fig. 5d). In summary, Py immunoreactivity developed progressively in the postnatal rat hippocampus with a specificity of staining parallel to that of the adult.

\section{Staining with Py in hippocampal grafts}

We were interested to know whether Py antigen would be synthesized by cells removed from their normal situation. Was its expression constitutive or did it depend on cell interactions only present in situ? The results of Py staining of E18 hippocampal fragments transplanted into adult hosts for 12 weeks were consistent with the patterns of immunoreactivity seen in the hippocampal fields from which the grafts were derived. Thus, the great majority of cells in subdissected $\mathrm{CA} 1$ and dentate granule grafts were Py-negative, while subdissected CA3 fragments contained almost exclusively Py-positive neurons. Figure $6 a$ shows an example of the latter with an abundance of large neurons intensely stained by Py. The in vivo orientation of these cells into a row has been lost in this graft, an observation consistent with previous results from pyramidal transplants (e.g., Raisman and Ebner, 1983, figure 15). In marked contrast, grafted CA1 pyramidal cells were only visible by virtue of the thionin counterstaining of their nuclei (Fig. 6b). Py-positive varicose processes were observed in the regions of grafts that lacked immunostained cell bodies. These processes were presumably derived from cells in host hippocampus. The specificity of Py 

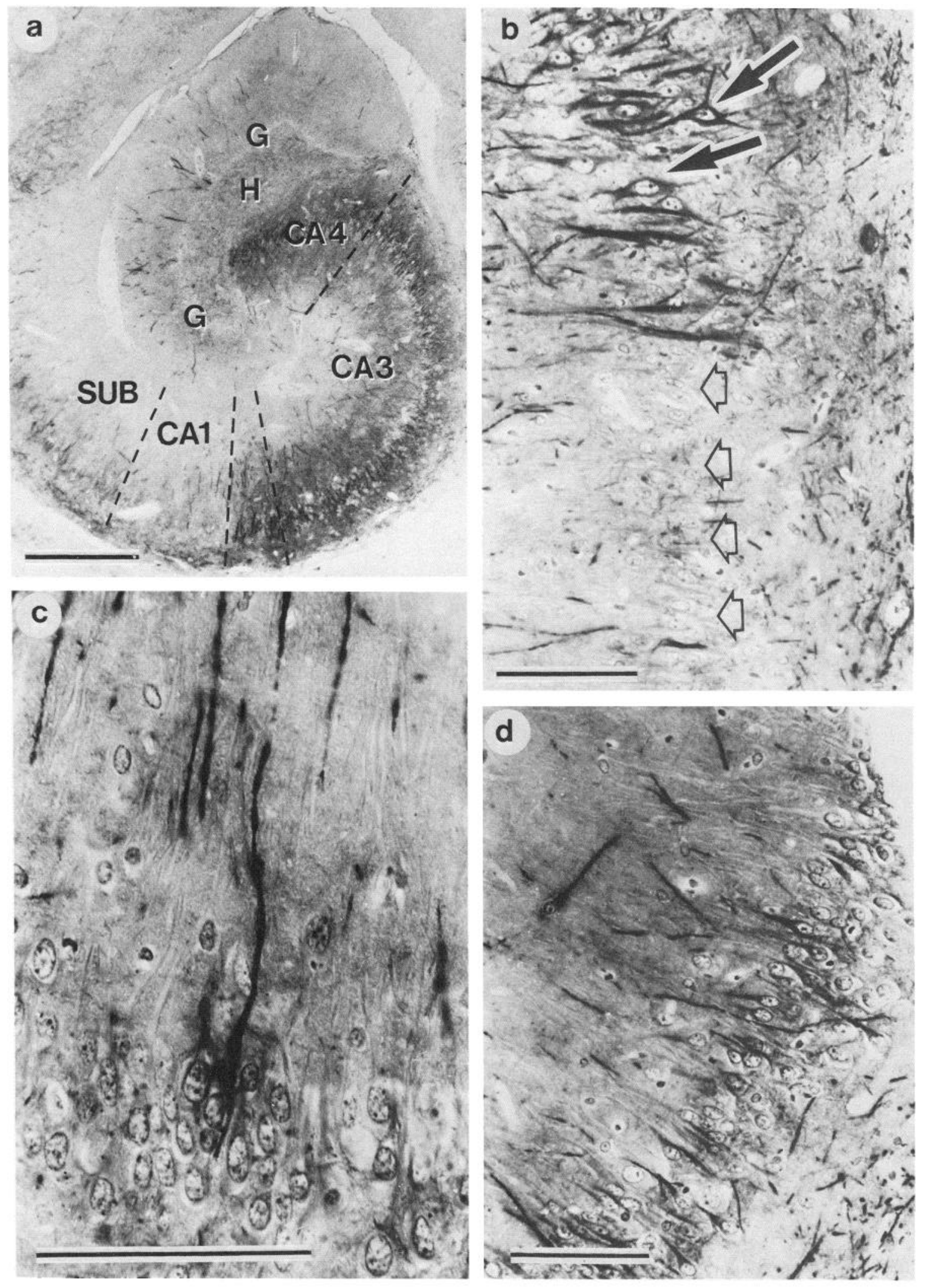

Figure 2. Py staining (with cobalt intensification) of hippocampus. $a$, Horizontal section at low magnification showing distribution of the antigen predominantly in fields CA3 and CA4 $b$, Detail of field CA2 (between CA1 and CA3 in Fig. $2 a$ ) showing the positive large pyramidal neurons with prominent nucleoli (arrows) contrasting with unstained smaller pyramids of CA1 (open arrows). $c$, Detail of field CA1. $d$, Subiculum. $G$, dentate granule cell layer; $H$, hilus; $S U B$, subiculum. Scale bars: $a, 500 \mu \mathrm{m} ; b-d, 100 \mu \mathrm{m}$. 

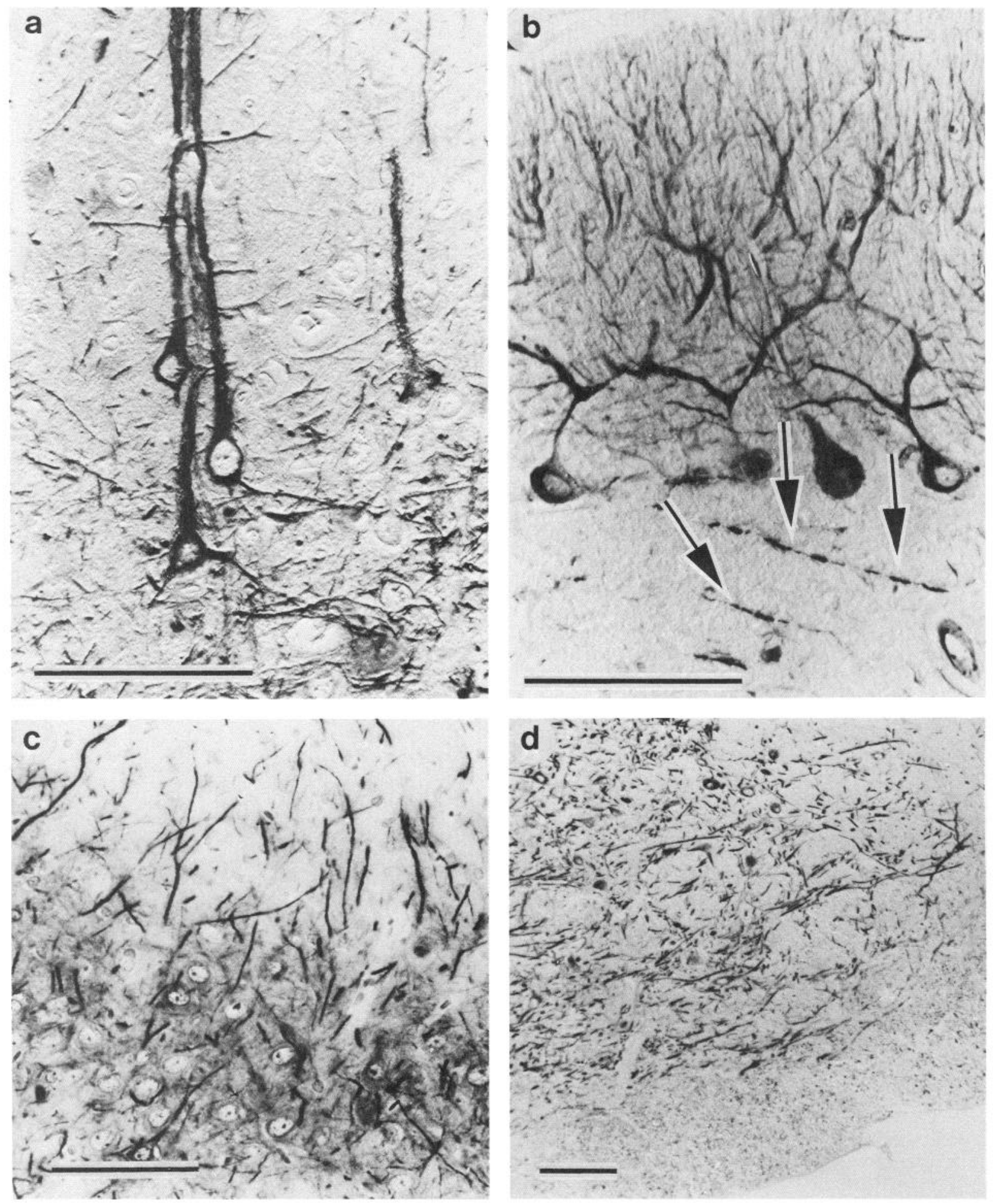

Figure 3. Py staining of (a) large pyramidal neurons in lamina V of cerebral cortex, $(b)$ cerebellar Purkinje cells (arrows indicate positive axons in the internal granule layer), $(c)$ branching apical dendrites in lamina I of cerebral cortex; $(d)$ substantia nigra at low magnification. $a, b$, and $d$, interference contrast; $c$, cobalt intensification. Scale bars, $100 \mu \mathrm{m}$.

staining was clearly demonstrated in the transitional zone grafts (Fig. 6, $c, d$ ). Groups of Py-negative cells, assumed to be granule neurons, were readily distinguished from less well organized clumps of Py-positive perikarya, assumed to be hilar interneurons and CA3 pyramids. The "granule" neurons were characterized by their smaller size and lack of a prominent nucleolus and were often tightly packed together either in rows or in a V-shape wrapped around a "hilar" group of stained pyramids, as seen in situ. Thus, for these transplants, expression of Py antigen can be taken to be constitutive and appears to occur in the same cells that synthesize the antigen in normal hippocampus. 

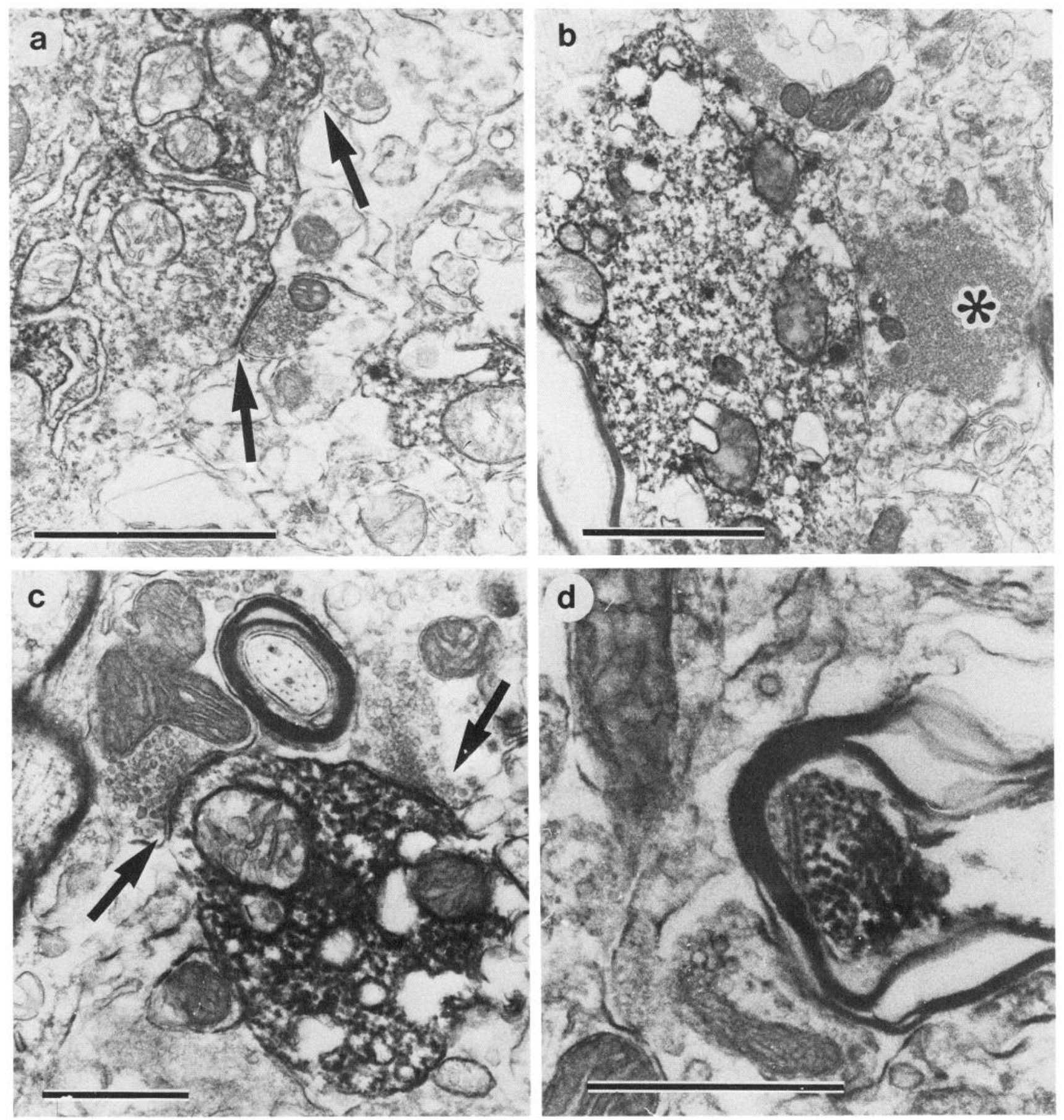

Figure 4. Ultrastructural immunocytochemistry with Py. $a$, Detail of a positive CA3 pyramidal cell, showing unstained axosomatic terminals (arrows) and widespread immunostaining within the perikaryon. $b$, Oblique cross section of the proximal portion of a Py-positive CA3 pyramidal dendrite that bears a typical shaft contact from a mossy fiber terminal $(*)$ containing densely packed synaptic vesicles. $c$, Cross section of a Pypositive dendrite with 2 asymmetrical shaft synapses (arrows). $d$, Detail of a Py-positive myelineated axon in the stratum radiatum of field CA3. Scale bars: $a$ and $b, 0.5 \mu \mathrm{m} ; c$ and $d, 0.2 \mu \mathrm{m}$.

\section{Staining of hippocampal cultures}

Cultures of fragments subdissected from E18 hippocampal primordia were examined for Py immunostaining after $17 \mathrm{~d}$ in vitro. This age was chosen because it is equivalent chronologically to the beginning of the third postnatal week, a developmental age when strong immunoreactivity is present in the hippocampus in situ. Numerous immunopositive neurons were seen in cultures derived from fragments of the CA3 field (Fig. 7). They represented a subset of neurons in the cultures (Fig. $7 a$ ) and were almost always large in size. The majority were pyramidal-like (Fig. $7 b$ ) with a single dominant dendrite, while others were stellate with several similarly sized dendritic processes radiating from the perikaryon in all directions. Occasional positive bipolar and fusiform neurons were also seen. The morphologies of many immunopositive neurons are consistent with 

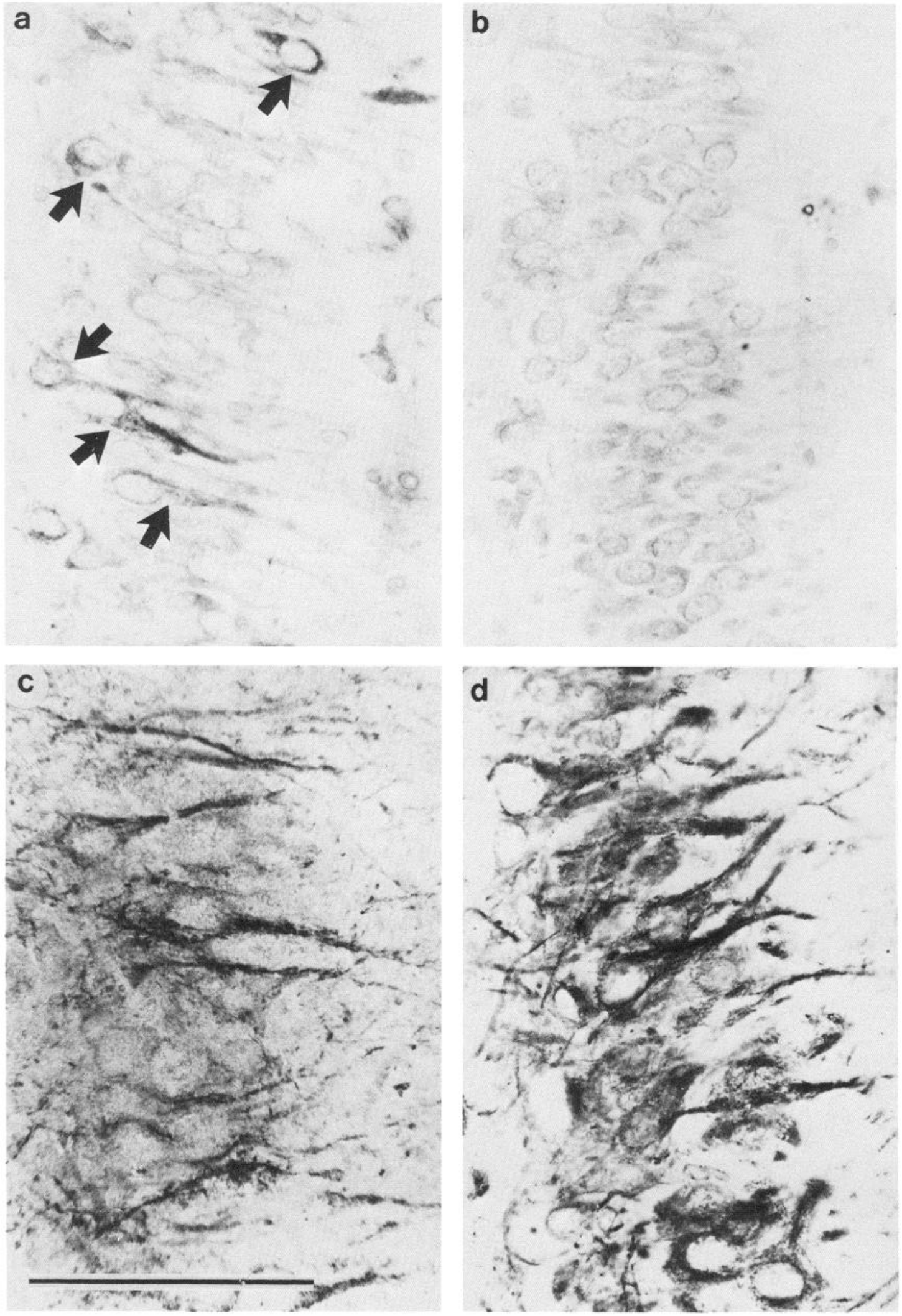

Figure 5. Development of Py staining in hippocampal field CA3 at (a) P5 (arrows indicate positive cells), (c) P10, and (d) P14. b, A control incubation at P5. Scale bar, $100 \mu \mathrm{m}$. 

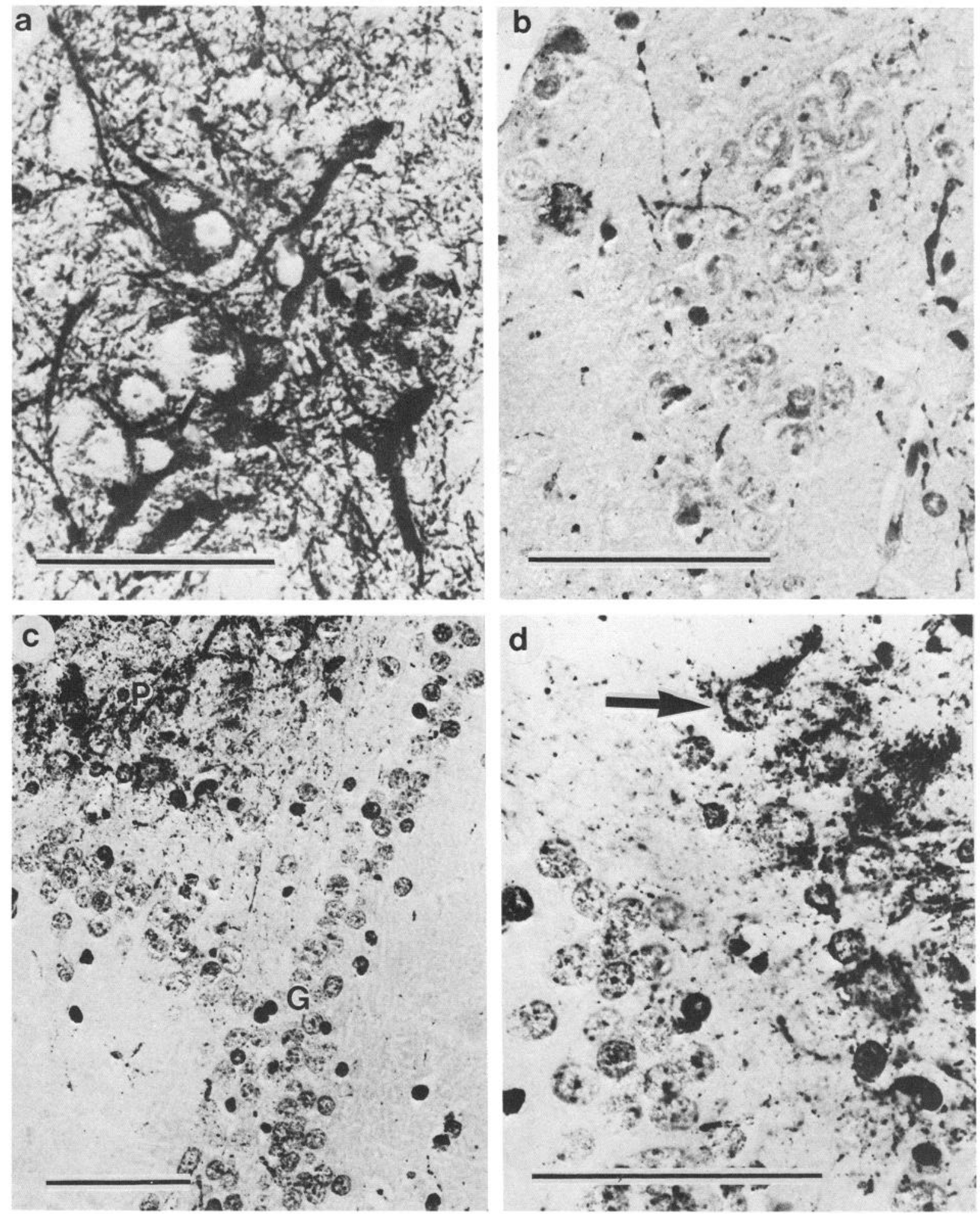

Figure 6. Py staining in grafts of subdissected hippocampal fragments with silver intensification of the reaction product and thionin counterstaining: $a$, CA 3 graft, showing a group of large positive cells; $b$, CA1 graft with Py-negative cells; $c$, grafted fragment of transitional zone (see text) showing both positive pyramidal cells $(P)$ and negative granule cells $(G) ; d$, detail of the same graft as $(c)$ showing a positive cell with pyramidal-like morphology (arrow). Scale bars, $200 \mu \mathrm{m}$. 

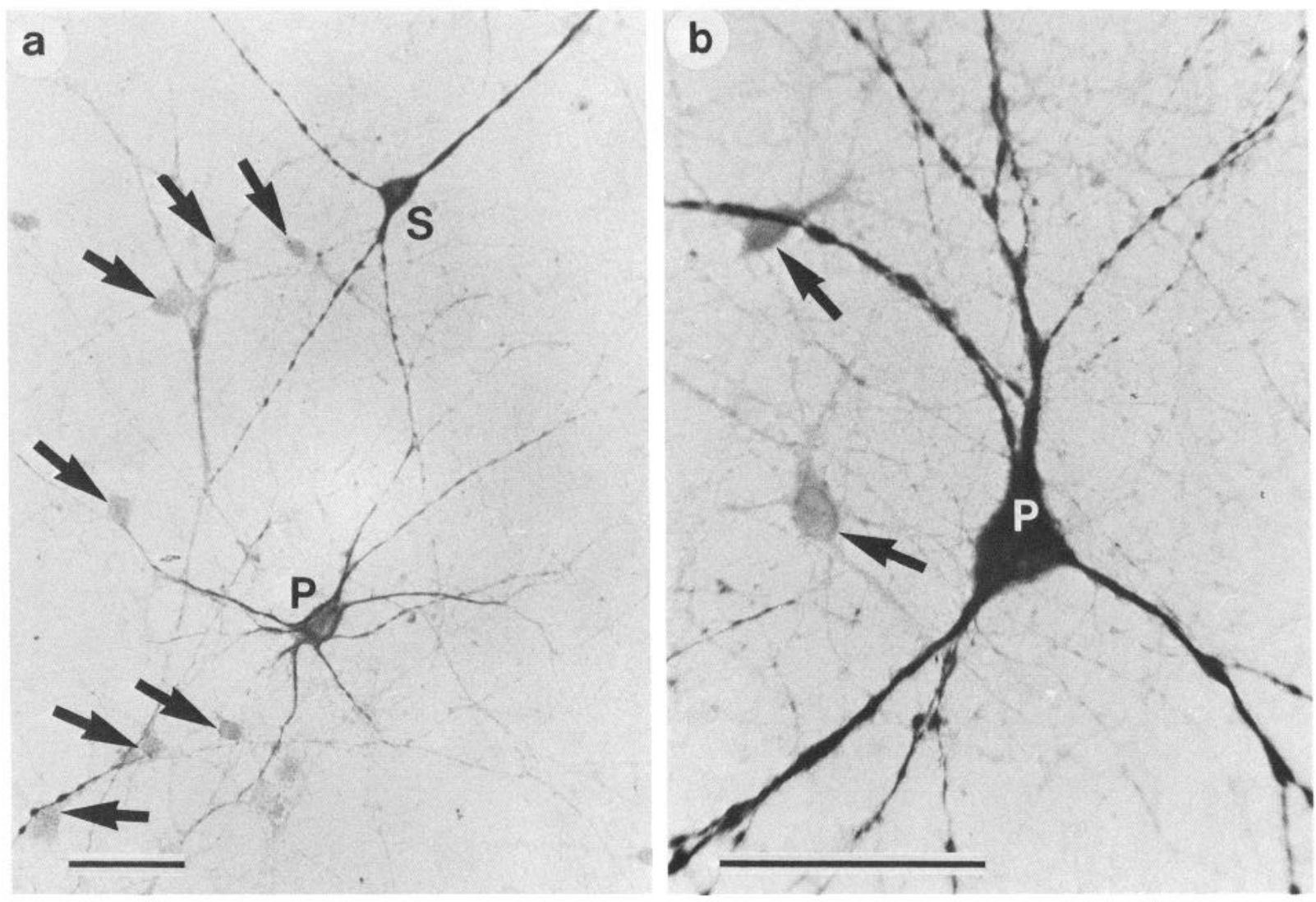

Figure 7. Py immunostaining of dissociated cultures of subdissected CA3 fragments after $17 \mathrm{~d}$ in vitro showing $(a)$ positive stellate- $(S)$ and pyramidal-like $(P)$ neurons and $(b)$ detail of a pyramidal-like cell $(P)$. Unstained neurons are arrowed. Scale bars, $50 \mu \mathrm{m}$.

their identification as $\mathrm{CA} 3$ pyramids. Multipolar neurons with more varicose processes (e.g., Fig. $7 a$, cell S) may represent interneurons, although direct extrapolation of cellular morphology observed in vitro from that seen in vivo is not a definitive means of identifying cells. The forms of cells observed in these cultures had similarities with those described elsewhere (Banker and Cowan, 1979; Banker and Waxman, 1988).

\section{Identification of Py antigen}

We have made initial attempts to identify the Py antigen by blotting SDS gels of samples prepared from various brain areas and from whole brains of different ages. A heavily labeled band of $M_{r} 146 \mathrm{kDa}$ appeared in immunoblots of samples of $\mathrm{P} 21$ rat brain (Fig. 8, lane 3). This band was represented with weaker intensity in P16 samples, and was absent at P6. A minor band of $M_{r} 166 \mathrm{kDa}$ appeared exclusively in the P21 sample of whole brain, possibly representing a posttranslationally modified form of the antigen, differing from the $146 \mathrm{kDa}$ protein in, for example, the degree of glycosylation. There was a constant faint staining of background bands in all samples. When equal amounts of total protein from different subdissected brain regions were compared, the most intense labeling was found in samples of cerebral cortex (Fig. 8, lane 6). Cerebellar samples also displayed fairly heavy labeling (lane 5). The $M_{r} 146 \mathrm{kDa}$ band was undetectable in samples of hippocampus, brain stem, or olfactory bulb (lanes 4,7 , and 8 , respectively) without a longer exposure of the same blot. This $146 \mathrm{kDa}$ band also appeared with the same mobility in samples that were not reduced prior to elec- trophoresis, indicating that the protein is not associated with another polypeptide species via disulfide bonds.

\section{Discussion}

We have shown that it is possible to use the monoclonal antibody approach to generate a cell marker that distinguishes between the major classes of hippocampal neurons: CA3/4 pyramids versus adjacent dentate granule cells, and CA 3 versus CA1 pyramidal neurons. This distinction is maintained throughout development and also appears in grafted hippocampal fragments. The antigen is also expressed in a subset of neurons in cultures of dissociated hippocampus. Thus, antibody Py seems to be a constitutive marker for the identification of hippocampal cells removed from their normal anatomical context. Since Py also recognizes subsets of neurons elsewhere in the brain, it may likewise be of use in studies of areas other than the hippocampus.

It is interesting that the expression of Py antigen is not solely determined by cytoarchitectonic field. Hilar cells and occasional scattered cells in other hippocampal fields were, like CA3 pyramids, immunopositive. The varicose nature of their dendritic processes and the size and position of the perikarya are consistent with these cells being GABAergic interneurons (Amaral, 1978; Ribak and Anderson, 1980; Schwartzkroin and Kunkel, 1985; Lacaille et al., 1987).

The Py antigen was identified as a $146 \mathrm{kDa}$ polypeptide by immunostaining of Western blots. The intensity of bands taken to represent Py antigen correlated well with the temporal and 


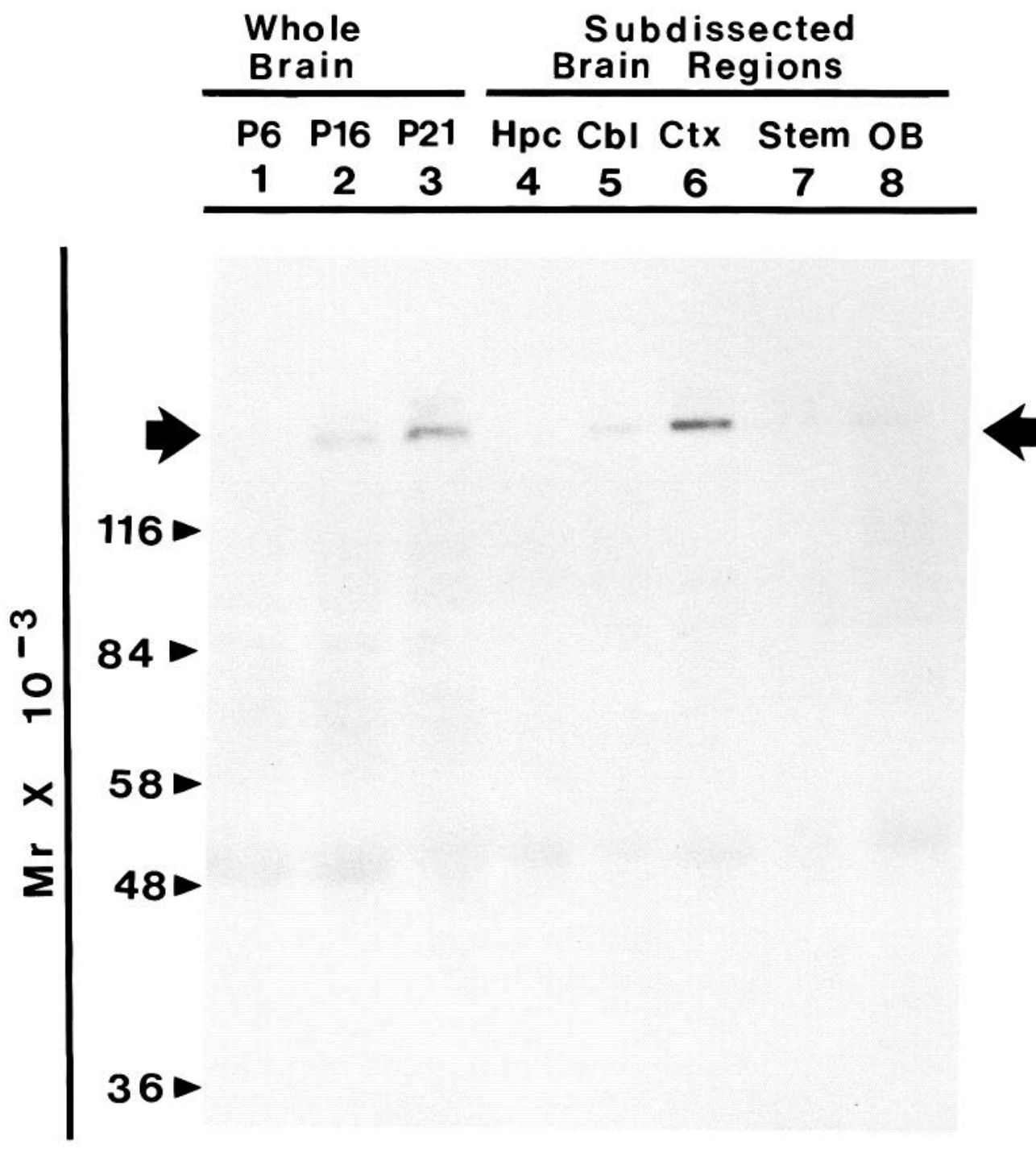

Figure 8. Immunoblot with Py showing a major immunoreactive band of $M_{r} 146 \mathrm{kDa}$ and an additional band (lane 3 ) at $166 \mathrm{kDa}$. Identical protein loading in each track. Samples were whole brain at P6 (lane 1), P16 (2), and P21 (3); adult hippocampus (4), cerebellum (5), cerebral cortex (6), brain stem (7), and olfactory bulb (8).

spatial patterns of Py staining observed by immunocytochemistry. The cerebral cortex, with its abundant large pyramidal cells expressing Py antigen, gave the highest intensity of staining on the immunoblots. Next in intensity was the cerebellum, in which all the Purkinje cells were Py-positive. Lesser amounts of antigen were present in equivalent samples from other brain regions such as hippocampus, brain stem, and olfactory bulb. Longer exposure of autoradiograms was required to reveal the $M_{r} 146 \mathrm{kDa}$ component in these samples. The low overall content of Py antigen in the hippocampal samples is consistent with its presence in only a subset of pyramidal cells in this region.

The PY antibody is a particularly useful marker for hippocampal neurons because its distribution complements that of the vitamin D-dependent calcium-binding protein (cholecalcin or calbindin; Jande et al., 1981; Baimbridge and Miller, 1982; Garcia-Segura et al., 1984). Antibodies to the latter show an almost reciprocal distribution to Py, with strong staining of CA1 pyramids and dentate granule cells (Feldman and Christakos, 1983; Rami et al., 1987). Most other antibodies reported to stain hippocampus (Levitt, 1984; Moskal and Schaffner, 1986; Arimatsu et al., 1987; Hendry et al., 1988) have broader patterns of specificity, although the 2F12 and 3F12 antibodies of Miller and Benzer (1983) distinguish pyramidal from granule neurons, and in the case of 3F12, between pyramids of different CA fields (Hinton et al., 1988). Transmitter immunohistochemistry might be an alternative means of distinguishing between hippocampal neurons. It is thought, however, that all the principal neurons of the hippocampal formation use glutamate as transmitter (Altschuler et al., 1985; Ottersen and Storm-Mathisen, 1985), though it is possible to distinguish these cells from interneurons via the latter's use of GABA. The granule cells of the dentate gyrus contain the opioid peptides enkephalin and dynorphin (Stengaard-Pedersen et al., 1981; McGinty et al., 1983; White et al., $1987)$ and the feasibility of using peptide antibodies in transplant experiments has already been demonstrated (Zimmer and Sunde, 1984). Parvalbumin may be an additional marker for GABA-ergic interneurons (Celio and Heizmann, 1981), and other potentially useful differences between cell types are provided 
by the differential distributions of enzymes such as protein kinase C (Wood et al., 1986; Saito et al., 1988).

The present report illustrates the utility of monoclonal antibodies for identification of the unique characteristics of subpopulations of neurons. Highly specific markers such as Py will be invaluable in morphological and functional analyses of the events taking place in the establishment of CNS connectivity and in regeneration.

\section{References}

Altschuler, R. A., D. T. Monaghan, W. G. Haser, R. J. Wenthold, N. P. Curthoys, and C. W. Cotman (1985) Immunocytochemical localization of glutaminase-like and aminotransferase-like immunoreactivities in the rat and guinea pig hippocampus. Brain Res. 330 . 225-233.

Amaral, D. G. (1978) A Golgi study of cell types in the hilar region of the hippocampus in the rat. J. Comp. Neurol. 182: 851-914.

Arimatsu, Y., J. K. Naegele, and C. J. Barnstable (1987) Molecular markers of neuronal subpopulations in layers 4,5 , and 6 of cat primary visual cortex. J. Neurosci. 7: 1250-1263.

Baimbridge, K. G., and J. J. Miller (1982) Immunohistochemical localization of calcium-binding protein in the cerebellum, hippocampal formation and olfactory bulb of the rat. Brain Res. 245: 223-229.

Banker, G. A., and W. M. Cowan (1979) Further observations on hippocampal neurons in dispersed cell culture. J. Comp. Neurol. 187 : 469-494.

Banker, G. A., and A. B. Waxman (1988) Hippocampal neurons generate natural shapes in cell culture. In Intrinsic Determinants of Neuronal Form and Function, R. J. Lasek and M. M. Black, eds., pp. 6182, Liss, New York.

Barclay, A. N., M. Letarte-Muirhead, and A. F. Williams (1975) Purification of the Thy-1 molecule from rat brain. Biochem. J. 151:699706

Celio, M. R., and C.W. Heizmann (1981) Calcium-binding protein parvalbumin as a neuronal marker. Nature 293: 299-302

de Groot, J. (1967) The Rat Brain in Stereotaxic Coordinates, N. V. Noord-Hollansche Uitgevers Maatschappij, Amsterdam.

Feldman, S. C., and S. Christakos (1983) Vitamin D-dependent calcium-binding protein in rat brain: Biochemical and immunocytochemical characterisation. Endocrinology 112: 290-302.

Gallyas, F., T. Görcs, and I. Merchenthaler (1982) High grade intensification of the end product of diaminobenzidine reaction demonstrating peroxidase activity. J. Histochem. Cytochem. 30: 183-184.

Garcia-Segura, L. M., D. Baetens, J. Roth, A. W. Norman, and L. Orci (1984) Immunohistochemical mapping of calcium-binding protein immunoreactivity in the rat central nervous system. Brain Res. 296: $75-86$.

Hartree, E. F. (1972) Determination of protein: A modification of the Lowry method that gives a linear photometric response. Anal. Biochem. 48: 422-427.

Hendry, S. H. C., F. G. Jones, S. Hockfield, and R. D. G. McKay (1988) Neuronal populations stained with the monoclonal antibody Cat-301 in the mammalian cerebral cortex and thalamus. J. Neurosci. 8: 518542.

Hinton, D. R., V. W. Henderson, J. C. Blanks, M. Rudnicka, and C. A. Miller (1988) Monoclonal antibodies react with neuronal subpopulations in the human nervous system. J. Comp. Neurol. 267: 398-408.

Jande, S. S., S. Tolnai, and D. E..M. Lawson (1981) Immunohistochemical localization of vitamin D-dependant calcium-binding protein in duodenum, kidney, uterus and cerebellum of chickens. Histochemistry 71:99-116.

Lacaille, J.-C., A. L. Mueller, D. D. Kunkel, and P. A. Schwartzkroin (1987) Local circuit interactions between oriens/alveus interneurons and CA 1 pyramidal cells in hippocampal slices. J. Neurosci. 7: 19791993.

Laemmli, U. K. (1970) Cleavage of structural proteins during the assembly of the head of bacteriophage T4. Nature 227:680-685.

Letarte-Muirhead, M., A. N. Barclay, and A. F. Williams (1975) Purification of the Thy-1 molecule, a major cell-surface glycoprotein of rat thymocytes. Biochem. J. 151: 685-697.
Lcvitt, P. (1984) A monoclonal antibody to limbic system neurons. Science 223: 299-301.

Lindsay, R. M., G. Raisman, and P. J. Seeley (1987) Intracerebral transplantation of cultured neurons after reaggregation in a plasma clot. Neuroscience 21: 683-698.

Lowry, O. M., N. J. Rosebrough, A. L. Farr, and R. J. Randall (1951) Protein measurement with the Folin phenol reagent. J. Biol. Chem. 193: 265-275.

McGinty, J. F., S. J. Henriksen, A. Goldstein, L. Terenius, and F. E. Bloom (1983) Dynorphin is contained with hippocampal mossy fibres: Immunochemical alterations after kainic acid administration and colchicine-induced neurotoxicity. Proc Natl. Acad. Sci. USA 80: 589-593.

Miller, C. A., and S. Benzer (1983) Monoclonal antibody cross-reactions between Drosophila and human brain. Proc. Natl. Acad. Sci. USA 80: 7641-7645.

Morris, R. J., and P. C. Barber (1983) Fixation of Thy-1 in nervous tissue for immunohistochemistry: A quantitative assessment of the effect of different fixation conditions upon retention of antigenicity and the cross-linking of Thy-1. J. Histochem. Cytochem. 31: 263274.

Moskal, J. R., and A. E. Schaffner (1986) Monoclonal antibodies to the dentate gyrus: Immunocytochemical characterization and flow cytometric analysis of hippocampal neurons bearing a unique cellsurface antigen. J. Neurosci. 6: 2045-2053.

Ottersen, O. P., and J. Storm-Mathisen (1985) Different neuronal localization of aspartate-like and glutamate-like immunoreactivities in the hippocampus of rat, guinea-pig and Senegalesle baboon (Papio papio), with a note on the distribution of $\gamma$-aminobutyrate. Neuroscience 16: 589-606.

Raisman, G., and F. F. Ebner (1983) Mossy fibre projections into and out of hippocampal transplants. Neuroscience 9: 783-801.

Rami, A, A. Bréhier, M. Thomasset, and A. Rabie (1987) Cholecalcin (28-kDa calcium-binding protein) in the rat hippocampus: Development in normal animals and in altered thyroid states. Dev. Biol. 124: 228-238.

Ribak, C. E., and L. Anderson (1980) Ultrastructure of the pyramidal basket cells in the dentate gyrus of the rat. J. Comp. Neurol. 192: 903-916.

Saito, N., U. Kikkawa, Y. Nishizuka, and C. Tanaka (1988) Distribution of protein kinase C-like immunoreactive neurons in rat brain. J. Neurosci. 8: 369-382.

Sajovic, P., E. Moraru, L. A. Greene, and M. Shelanski (1986) Selective staining of large projection neurons by monoclonal antibody to a glycoprotein of PC12 cells. J. Neurosci. 6: 82-93.

Schwartzkroin, P. J., and D. D. Kunkel (1985) Morphology of identified interneurons in the CA1 regions of guinea pig hippocampus. J. Comp. Neurol. 232: 205-218.

Seeley, P. J., and P. M. Field (1988) Use of colloidal gold complexes of wheat germ agglutinin as a label for neural cells. Brain Res. 449: 177-191.

Stengaard-Pedersen, K., K. Fredens, and L.-I. Larsson (1981) Enkephalin and zinc in the hippocampal mossy fibre system. Brain Res. 212: 230-233.

Webb, M., and P. L. Woodhams (1984a) Monoclonal antibodies recognising cell surface molecules expressed by rat cerebellar interneurons. J. Neuroimmunol. 6: 283-300.

Webb, M., and P. L. Woodhams (1984b) Recognition by a mouse monoclonal antibody of a glycoprotein antigen of rat brain which is expressed intracellularly by neurones. Neuroscience $13: 583-594$.

White, J. D., C. M. Gall, and J. F. McKelvy (1987) Enkephalin biosynthesis and enkephalin gene expression are increased in hippocampal mossy fibres following a unilateral lesion of the hilus. J. Neurosci. 7: 753-759.

Wood, J. G., P. R. Girard, G. J. Mazzei, and J. F. Kuo (1986) Immunocytochemical localization of protein kinase $C$ in identified neuronal compartments of rat brain. J. Neurosci. 6: 2571-2577.

Zhou, C.-F., G. Raisman, and R. J. Morris (1985) Specific patterns of fibre outgrowth from transplants to host mice hippocampi, shown immunohistochemically by the use of allelic forms of Thy-1. Neuroscience 16: 819-833.

Zimmer, J., and N. Sunde (1984) Neuropeptides and astroglia in intracerebral hippocampal transplants: An immunohistochemical study in the rat. J. Comp. Neurol. 227: 331-347. 